\title{
Problem solving and creative thinking ability of High School children
}

\author{
PRIYA KUMARI AND LATA PUJAR
}

Received: 27.01.2014; Accepted: 09.11.2014

See end of the paper for authors' affiliations PRIYA KUMARI

Department of Human Development and Family Studies, Rural Home Science College, University of Agricultural

Sciences, DHARWAD (KARNATAKA) INDIA Email: priyakumari044@gmail. com
ABSTRACT : The study was conducted to know the problem solving and creative thinking ability of High School children. Sample of 300 High School children from teenage group 13-16 years of both sex, studying in $8^{\text {th }}$ and $9^{\text {th }}$ standard were selected from government and private schools of Dharwad district. General problem solving ability of the students was assessed by using check list and mathematical problem solving ability of children was assessed by Problem solving ability inventory developed by Dubey (2010).Creative thinking scale developed by Mehdi (1989) was used to assess the creative thinking ability of children. Results revealed that majority of the children had medium level of general and mathematical problem solving ability and high level of creative thinking ability. Gender has significant influence on problem solving ability however girls performed better in general problem solving ability than boys, whereas boys performed better than girls in mathematical ability.

KEY WORDS: Problem solving, Creative thinking, Inventory

口 HOW TO CITE THIS PAPER : Kumari, Priya and Pujar, Lata (2014). Problem solving and creative thinking ability of High School children. Asian J. Home Sci., 9 (2) : 594-597. 